\title{
THE ESTIMATION OF HEPATIC BLOOD FLOW AND INTRAHEPATIC SHUNTED BLOOD FLOW BY COLLOIDAL HEAT-DENATURED HUMAN SERUM ALBUMIN LABELED WITH I ${ }^{131}$
}

\author{
By STANLEY SHALDON, LIVIO CHIANDUSSI,* LUIS GUEVARA, † JOHN CAESAR $\ddagger$ \\ AND SHEILA SHERLOCK
}

(From the Department of Medicine, The Royal Free Hospital, London, England)

(Submitted for publication January 30, 1961 ; accepted February 27, 1961)

The measurement of hepatic blood flow based upon the rate of disappearance of colloidal particles from peripheral blood by the Kupffer cells depends upon two basic assumptions: 1) that the colloid is completely removed from the blood in one passage through the liver, and 2) that the liver is its sole source of removal. Dobson and Jones (1) showed in animals that radioactive colloidal chromic phosphate approximated satisfactorily to these theoretical postulates, although the efficiency of hepatic extraction of this colloid has not been determined in man. Radioactive colloidal gold has also been used as an index of liver blood flow, and in the original work of Vetter, Falkner and Neumayr (2) the hepatic extraction efficiency averaged 80 per cent in three subjects. In a later paper (3), however, Vetter and co-workers reported a lower average hepatic blood flow in normal subjects, and subsequently it has been shown that commercial preparations of radiogold are not suitable for measurement of hepatic blood flow, since their particle sizes are not homogeneous (4, $5)$.

Halpern and colleagues (6) described a heatdenatured albumin colloidal complex labeled with $\mathrm{I}^{131}\left(\mathrm{CAI}^{131}\right)$. The particle size could be controlled by the extent of heating and checked by biological standardization. Preliminary results in animals and in man suggested that extrahepatic removal was minimal and hepatic extraction was over 90 per cent (7-9). This colloid might therefore be suitable for measuring liver blood flow and our communication deals with its use for this purpose in control subjects and patients with cirrhosis. The results suggest that the method is valid for

\footnotetext{
* British Empire Cancer Campaign Research Fellow; present address: Istituto Patologia Medica, Turin, Italy.

$\dagger$ Rockefeller Foundation Traveling Fellow; present address: Hospital de Enfermedades de la Nutricion, Mexico, D. F., Mexico.

$\$$ British Council Scholar.
}

measuring liver blood flow in normal subjects. It underestimates total liver blood flow in patients with cirrhosis by the amount of blood shunted through intrahepatic portal-hepatic venous anastomoses which are not lined by Kupffer cells and hence do not remove the colloid.

\section{METHODS}

Patients. The following groups of subjects were studied: I, 14 control subjects without known liver disease; II, 21 cirrhotic patients with a patent portal vein; III, 11 cirrhotic patients with a portacaval anastomosis (including two patients in whom preoperative studies were made) and 1 patient with thrombosis of the portal vein; IV, 3 patients with an extrahepatic portal vein block and normal liver structure. The state of the portal vein was checked by splenic venography in all patients with liver disease.

$C A I^{131}$. The preparation of $\mathrm{CAI}^{131}$ is described in the Appendix.

The estimation of minimal hepatic blood flow without hepatic vein catheterization. A known amount of $\mathrm{CAI}^{131}$ containing approximately $0.1 \mathrm{mg}$ per $\mathrm{kg}$ body weight of colloidal albumin and 15 to $20 \mu \mathrm{c}$ of $\mathrm{I}^{131}$ in a volume of 1 to $2 \mathrm{ml}$ was injected intravenously, after preliminary thyroid blockade with potassium iodide, $200 \mathrm{mg}$ daily for 3 days. Six-ml arterial blood samples were taken into heparinized tubes from a polyethylene catheter in the femoral artery at $3,4,5,6,8,10,15,20$ and 30 minutes after injection. In some patients, further samples were obtained at 10-minute intervals up to 1 hour after injection, and in one subject blood samples were obtained at 4 -hour intervals over 24 hours.

Estimation of hepatic extraction of $C A I^{131}$ and measurement of total hepatic blood flow. The technique was identical with that described for the measurement of minimal hepatic blood flow except that hepatic vein samples were obtained from a no. 9 radiopaque catheter which had been placed under fluoroscopic control in one of the main right hepatic veins. The hepatic venous samples were taken simultaneously with the arterial samples after allowing for the dead space sampling time of the hepatic vein catheter. In certain subjects hepatic blood flow was measured by the Fick principle (10) with a constant infusion of indocyanine green (11-13) at the same time that total hepatic blood flow was measured by $\mathrm{CAI}^{131}$. 
Determination of $C A I^{131}$ activity. The amount of $\mathrm{CAI}^{131}$ injected was determined by weighing syringes before and after injection. The volume injected was calculated from the weight and specific gravity of $\mathrm{CAI}^{131}$. The total activity injected was calculated from the activity of a measured standard of $\mathrm{CAI}^{131}$ which had been diluted to a known volume. The activity of the samples was measured in plasma after the blood had been centrifuged at $3,000 \mathrm{rpm}$ for 15 minutes. All samples were counted in a well scintillation counter to a minimum of 5,000 counts. After counting total activity in the plasma $\left(\mathrm{P}_{\mathrm{TA}}\right)$ the protein-bound iodine was precipitated with trichloroacetic acid and the supernatant recounted for free $\mathrm{I}^{131}$ activity $\left(P_{F I}\right)$. This value was subtracted from $P_{T A}$ to give protein-bound activity $\left(\mathrm{P}_{\mathrm{C}}\right)$. Free iodine $\mathrm{I}^{131}$ was not found in any sample before 10 minutes after injection. Plasma volumes were calculated from the initial extrapolated $\mathrm{CAI}^{131}$ disappearance slope $(a)$ and in several patients by the Evans blue dye technique (14). Hematocrits were measured after centrifugation of hepatic venous and arterial blood at 3,000 rpm for 30 minutes and corrected for trapped plasma (15). Blood volumes were calculated from plasma volumes and corrected hematocrit values.

\section{Calculations}

Minimal hepatic blood flow (Figure 1). Peripheral plasma total activity and peripheral plasma proteinbound activity were plotted on a semilogarithmic scale against time. As $\mathrm{P}_{\mathrm{FI}}$ was not detected before 10 minutes, the initial slopes of $\mathrm{P}_{\mathrm{TA}}$ and $\mathrm{P}_{\mathrm{C}}$ were identical. The initial slope (a) was extrapolated to zero, and the calculated zero time activity $\left(\mathrm{P}_{0}\right)$ divided into the activity of $\mathrm{CAI}^{131}$ injected, to give the initial volume of distribution of $\mathrm{CAI}^{131}$ (plasma volume). After 10 to 15 minutes, $\mathrm{P}_{\mathrm{TA}}$ began to rise and coincided with the appearance of free $\mathrm{I}^{131}$ in the plasma, which latter was assumed to be due to the breakdown of the colloid complex within the liver and subsequent release of free $\mathrm{I}^{131}$ into the plasma. The subsequent decay of $\mathrm{P}_{T A}$ was followed in one subject and represented the resultant of release of free $\mathrm{I}^{131}$ from the liver and urinary loss, together with the removal of residual protein-bound $\mathrm{I}^{131}$ (particles of small size).

$P_{C}$ activity equaled $P_{T A}$ for the first 10 minutes, but after this time it followed a much shallower exponential slope $(b) ; b$ and $\mathrm{P}_{\mathbf{c}}$ decay were extrapolated to zero time and expressed as a percentage of $\mathrm{P}_{0}$, giving a percentage activity due to small particles of $\mathrm{CAI}^{131} ; b$, assumed to represent the clearance of small particles of $\mathrm{CAI}^{131}$ by the reticuloendothelial system outside the liver, was used as a biological standardization for each preparation of CAI ${ }^{131}$. In one subject, $b$ was followed for 24 hours, and accurate analysis of its exponential character was possible; $b$ was subtracted from $a$ and the resultant exponential slope $c$ used as the definitive clearance slope of $\mathrm{CAI}^{131}$ by the liver.

The rate constant for $c$ was calculated from the general equation for an exponential function:

$$
P_{t}=P_{0} e-k t
$$

By transposition

$$
K \min ^{-1}=\frac{\operatorname{Ln} 2}{t_{\frac{1}{2}}}=\frac{0.693}{t_{\frac{1}{3}}}
$$

where $P_{t}=$ plasma activity of $\mathrm{CAI}^{131}$ at time $t$ in minutes, $P_{0}=$ the activity at time zero determined by extrapolation of the slope and $K=$ fraction of retained plasma activity of $\mathrm{CAI}^{131}$ which was removed from the blood per minute.

If the plasma colloid is removed completely in one passage through the liver then the constant, $K$, represents the fraction of the circulating plasma or blood volume which perfuses the liver per minute. However, if the hepatic extraction $(E)$ of the colloid is less than 100 per cent, then $K$ underestimates the fraction of blood volume perfusing the liver by the percentage of the colloid not cleared by the liver in one passage.

If $E$ is not known, then the measurement of hepatic blood flow is called "minimal hepatic blood flow" (MHBF), since it is less than the total hepatic blood flow (THBF), and may be calculated from the equation

$$
\operatorname{MHBF}(\mathrm{ml} / \mathrm{min})=K \mathrm{~min}^{-1} \times \text { blood volume }
$$

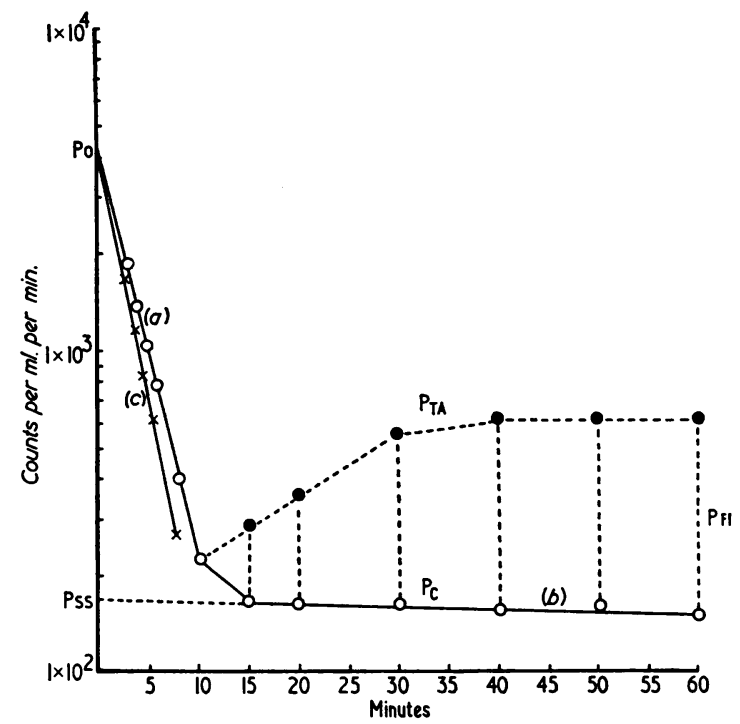

Fig. 1. Minimal hepatic blood flow (CONtrol, Subject 2). Activity of plasma $\mathrm{CAI}^{131}$ is plotted on a semilogarithmic scale against time. Slope $(c) t_{\frac{1}{2}}=2$ minutes; blood volume $=4,100 \mathrm{ml} ; K=0.346 \mathrm{~min}^{-1}$. Minimal hepatic blood flow $=4,100 \times 0.346=1,420 \mathrm{ml}$ per minute. $\mathrm{P}_{\mathrm{TA}}(\mathrm{O})=$ peripheral plasma total activity of $\mathrm{I}^{131}$ up to 10 minutes on slope $a$ and then as ( ). $\mathrm{P}_{\mathrm{FI}}=$ plasma free iodine activity which was not present before 10 minutes; subsequently it was subtracted from $\mathrm{P}_{\mathrm{TA}}(\bullet) . \quad \mathrm{P}_{\mathbf{C}}(\mathrm{O})=$ peripheral plasma activity corrected for free $\mathrm{I}^{131}$ and represented as $(\mathrm{O})$ on slope $b$. PSS = zero time activity of particles of small size from extrapolation of slope $b$. Slope $c$ is derived from graphical subtraction of slope $b$ from slope $a$. 


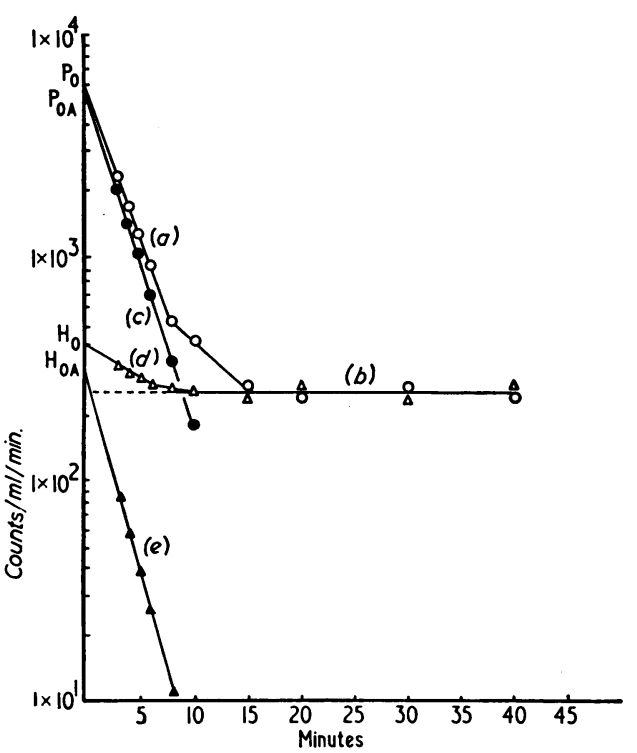

Fig. 2. Hepatic extraction of $\mathrm{CAI}^{131}$; minimal and total hepatic blood flows (CONTRol, Subject 1). Activity of arterial and hepatic venous plasma $\mathrm{CAI}^{131}$ is plotted on a semilogarithmic scale against time. Activity due to free $\mathrm{I}^{131}$ has already been subtracted. Hepatic extraction of $\mathrm{CAI}^{131}(E \%)=\left[\left(P_{0 A}-H_{0 A}\right) / P_{04}\right] \times 100=95 \%$. Slope $c t_{1}=1.75$ minutes; $K=0.396 \mathrm{~min}^{-1}$; blood volume $=5,250 \mathrm{ml}$. Minimal hepatic blood flow $=2,080 \mathrm{ml}$ per minute. Total hepatic blood flow $=(2,080 \times 100) / 95=$ $2,190 \mathrm{ml}$ per minute. Slope $a$ represents peripheral arterial plasma disappearance of $\mathrm{CAI}^{131}$ (O). Slope $b$ represents activity due to particles of small size, not removed by the liver $(O, \Delta)$. Slope $c(\bullet)$ represents disappearance of large particles of $\mathrm{CAI}^{131}$ in arterial plasma (slope $a-b$ ) extrapolated to zero time to give $P_{0 A}$. Slope $d(\triangle)$ represents hepatic venous plasma activity of $\mathrm{CAI}^{131}$. Slope $e(\boldsymbol{\Delta})$ represents large particles of $\mathrm{CAI}^{131}$ present in hepatic venous plasma $(d-b)$.

Hepatic extraction of $C A I^{131}$ and total hepatic blood flow (Figure 2). The peripheral plasma disappearance slope of $\mathrm{CAI}^{131}$ was calculated as described above. Hepatic venous samples were treated in an identical manner and the activity followed a two-component slope. The initial slope of disappearance in hepatic venous plasma (d) was extrapolated to zero time and the activity $\mathrm{H}_{0}$ determined. The slow component in the hepatic venous plasma identical with $b$ in the peripheral plasma was again assumed to represent particles of small size not cleared by the liver. Graphical subtraction of slope $b$ from slopes $a$ (peripheral plasma decay) and $d$ gave the resultant slopes $c$ and $e$. Slopes $c$ and $e$ were extrapolated to zero time to give $P_{0 A}$ and $H_{0 A}$, representing zero time concentrations of particles of $\mathrm{CAI}^{131}$ which were removed by the liver. The percentage extraction of $\mathrm{CAI}^{\mathbf{1 3 1}}$ by the liver in one passage was calculated from the formula:

$$
E_{-} \%=\frac{P_{0 \mathrm{~A}}-H_{0 \mathrm{~A}}}{P_{0 \mathrm{~A}}} \times 100
$$

Total hepatic blood flow was then calculated from minimal hepatic blood flow corrected for hepatic extraction (E) :

THBF (ml/min)

$$
\begin{aligned}
& =\frac{K \min ^{-1} \times \text { blood volume }(\mathrm{ml}) \times 100}{E} \\
& =\frac{\text { MHBF }}{E} \times 100
\end{aligned}
$$

Statistical analyses were performed by standard methods (16).

\section{RESULTS}

The percentage of particles of small size (PSS) averaged $5.72 \pm$ (1 SD) 1.33 for all preparations of $\mathrm{CAI}^{131}$. Any preparation with more than 8 per cent particles of small size was discarded. The plasma half-life of PSS was 13 hours and the

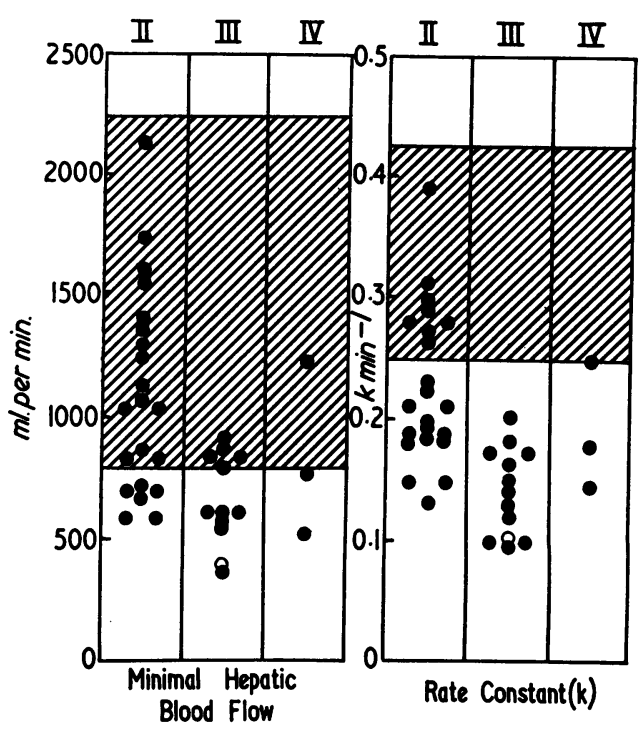

Fig. 3. Comparison of minimal hepatic blood flow (MHBF) AND RATE CONSTANT $K\left(\mathrm{CAI}^{131}\right)$. Group II : 21 patients with cirrhosis and a patent portal vein (mean $\mathrm{MHBF}=1,139 \pm 381 \mathrm{ml}$ per minute, $K=0.288 \pm 0.0634$ $\mathrm{min}^{-1}$. Group III : 11 patients with cirrhosis and a portacaval anastomosis (mean MHBF $681 \pm 169 \mathrm{ml}$ per minute, $\left.K=0.147 \pm 0.0364 \mathrm{~min}^{-1}\right)$. Group IV : 3 patients with extrahepatic portal vein obstruction; normal liver structure (mean MHBF $837 \mathrm{ml}$ per minute, $K=0.193$ $\left.\min ^{-1}\right)$. The mean $\mathrm{MHBF}$ for Groups II and III are significantly lower than the control group $(0.001<\mathrm{p}<$ 0.01 ) but the rate constants $K$ are even more significantly reduced $(\mathrm{p}<0.001)$. Shaded area equals control range (mean $\pm 2 \mathrm{SD}$ ) established from 14 subjects without liver disease for MHBF (1,516 $\pm 362 \mathrm{ml}$ per minute) and $K\left(0.339 \pm 0.044 \mathrm{~min}^{-1}\right) ;(O)=$ patient with cirrhosis and thrombosed portal vein in Group III. 
TABLE I

Minimal hepatic blood flow, hepatic extraction and total hepatic blood flow (CA I ${ }^{131}$ ), and estimated hepatic blood flow (indocyanine green) in control subjects and patients with liver disease*

\begin{tabular}{|c|c|c|c|c|c|c|c|}
\hline \multirow{2}{*}{$\begin{array}{c}\text { Case } \\
\text { no. }\end{array}$} & & \multirow[b]{2}{*}{ Diagnosis } & \multicolumn{4}{|c|}{$\mathrm{CAI}^{121}$} & \multirow{2}{*}{$\begin{array}{c}\text { Indocyanine } \\
\text { green } \\
\text { EHBF }\end{array}$} \\
\hline & & & $\boldsymbol{K}$ & MHBF & $E$ & THBF & \\
\hline \multirow{3}{*}{$\begin{array}{l}1 \\
2 \\
3 \\
4 \\
5 \\
6\end{array}$} & Group I control & & $\min ^{-1}$ & $m l / \min$ & $\%$ & $\mathrm{ml} / \mathrm{min}$ & $m l / m i n$ \\
\hline & Give 1, concis & $\begin{array}{l}\text { Peptic ulcer } \\
\text { Peptic ulcer } \\
\text { Sarcoidosis } \\
\text { Neurosis } \\
\text { Peptic ulcer } \\
\text { Peptic ulcer }\end{array}$ & $\begin{array}{l}0.396 \\
0.346 \\
0.308 \\
0.386 \\
0.346 \\
0.250\end{array}$ & $\begin{array}{r}2,080 \\
1,470 \\
920 \\
2,010 \\
1,650 \\
1,220\end{array}$ & $\begin{array}{l}95 \\
96 \\
93 \\
93 \\
92 \\
93\end{array}$ & $\begin{array}{r}2,190 \\
1,540 \\
980 \\
2,160 \\
1,790 \\
1,320\end{array}$ & $\begin{array}{r}950 \\
1,970 \\
1,290\end{array}$ \\
\hline & $\begin{array}{l}\text { Mean } \\
\text { SD }\end{array}$ & & & & $\begin{aligned} & 93.7 \\
\pm & 1.79\end{aligned}$ & $\begin{array}{r}1,663 \\
\pm \quad 478\end{array}$ & \\
\hline \multirow[t]{2}{*}{$\begin{array}{r}7 \dagger \\
8 \ddagger \\
9 \\
10 \\
11 \\
12\end{array}$} & $\begin{array}{l}\text { Group II, cirrhosis and } \\
\text { patent portal vein }\end{array}$ & $\begin{array}{l}\text { Postnecrotic } \\
\text { Postnecrotic } \\
\text { Postnecrotic } \\
\text { Postnecrotic } \\
\text { Postnecrotic } \\
\text { Postnecrotic }\end{array}$ & $\begin{array}{l}0.185 \\
0.198 \\
0.267 \\
0.386 \\
0.230 \\
0.147\end{array}$ & $\begin{array}{r}960 \\
1,080 \\
1,040 \\
2,100 \\
1,030 \\
800\end{array}$ & $\begin{array}{l}65 \\
90 \\
75 \\
72 \\
89 \\
64\end{array}$ & $\begin{array}{l}1,480 \\
1,190 \\
1,380 \\
2,940 \\
1,160 \\
1,250\end{array}$ & 1,390 \\
\hline & $\begin{array}{l}\text { Mean } \\
\text { SD }\end{array}$ & & & & $\begin{array}{ll} & 75.8 \\
\pm & 11.51\end{array}$ & $\begin{array}{r}1,566 \\
\pm \quad 684\end{array}$ & \\
\hline \multirow[t]{3}{*}{$\begin{array}{l}7 \dagger \\
8 \ddagger \\
13 \\
14 \\
15 \S\end{array}$} & $\begin{array}{l}\text { Group III, cirrhosis and } \\
\text { portacaval anastomosis or } \\
\text { thrombosed portal vein }\end{array}$ & $\begin{array}{l}\text { Postnecrotic } \\
\text { Postnecrotic } \\
\text { Postnecrotic } \\
\text { Postnecrotic } \\
\text { Alcoholic }\end{array}$ & $\begin{array}{l}0.173 \\
0.141 \\
0.115 \\
0.099 \\
0.102\end{array}$ & $\begin{array}{l}920 \\
780 \\
550 \\
600 \\
380\end{array}$ & $\begin{array}{l}86 \\
90 \\
90 \\
87 \\
95\end{array}$ & $\begin{array}{r}1,070 \\
860 \\
610 \\
690 \\
400\end{array}$ & $\begin{array}{l}770 \\
570 \\
740 \\
400\end{array}$ \\
\hline & $\begin{array}{l}\text { Mean } \\
\text { SD }\end{array}$ & & & & $\begin{array}{r}89.6 \\
\pm \quad 3.5\end{array}$ & $\begin{array}{r}726 \\
\pm \quad 226\end{array}$ & \\
\hline & $\begin{array}{l}\text { Group IV, portal vein } \\
\text { thrombosis and normal } \\
\text { liver structure }\end{array}$ & & & & & & \\
\hline 16 & & Sepsis & 0.150 & 510 & 92 & 550 & 560 \\
\hline
\end{tabular}

${ }^{*} K=$ rate constant of peripheral plasma slope of $\mathrm{CAI}^{131}$. $\mathrm{MHBF}=$ minimal hepatic blood flow. $\mathrm{E}=$ hepatic extraction of $C A I^{131}$ in one passage through the liver. $\mathrm{THBF}=$ total hepatic blood flow. EHBF $=$ estimated hepatic blood flow.

$\dagger \ddagger$ Before and after portacaval anastomosis.

$\S$ Thrombosed portal vein.

half-life in plasma of $\mathrm{P}_{\mathrm{TA}}$, after the initial extraction phase, was 24 hours $\left(\mathrm{P}_{\mathrm{C}}+\mathrm{P}_{\mathrm{FI}}\right)$.

There was no significant difference between 14 simultaneously determined plasma volumes using Evans blue and $\mathrm{CAI}^{131}$.

Minimal hepatic blood flow, hepatic extraction, and total hepatic blood flow (Figure 3, Table I)

Group I. Minimal hepatic blood flow in 14 control subjects averaged $1,516 \pm 362 \mathrm{ml}$ per minute, $K$ (fraction of blood volume perfusing the liver per minute) equaled $0.339 \pm 0.044$. In 6 of these control subjects $E$ was remarkably constant and averaged $93.7 \pm 1.79$ per cent in one passage through the liver. Total hepatic blood flow in these 6 subjects averaged $1,633 \pm 478 \mathrm{ml}$ per minute (Table I).

Group II. In 21 patients with cirrhosis and a patent portal vein, minimal hepatic blood flow averaged $1,139 \pm 381 \mathrm{ml}$ per minute and $K$ averaged $0.288 \pm 0.0634 \mathrm{~min}^{-1}$. Minimal hepatic blood flow was significantly reduced compared with the control group $(0.001<p<0.01)$, but $K$ was even more significantly reduced ( $p<$ 0.001 , Figure 3 ). In 6 of these patients $E$ was 


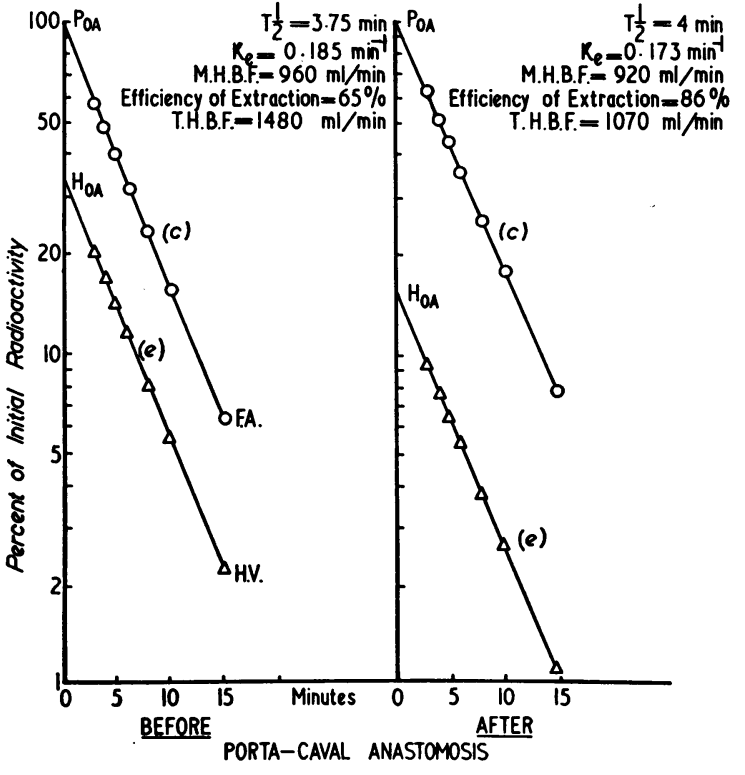

Fig. 4. EfFect of portacaval anastomosis on Hepatic extraction of $\mathrm{CAI}^{131}$ (cirrhotic, Subject 7). Arterial and hepatic venous plasma activity of $\mathrm{CAI}^{131}$ expressed as a percentage activity of zero time arterial activity has been plotted on a semilogarithmic scale against time after correction for slow components and free iodine. There has been a significant rise in hepatic extraction of $\mathrm{CAI}^{131}$ after operation. Total hepatic blood flow has been reduced by 28 per cent, but minimal hepatic blood flow has been reduced by only 5 per cent. M.H.B.F. = minimal hepatic blood flow; T.H.B.F. = total hepatic blood flow; F.A. = femoral arterial plasma; H.V. = hepatic venous plasma $c=$ definitive slope of $\mathrm{CAI}^{131}$ in arterial plasma; $e=$ definitive slope of $\mathrm{CAI}^{131}$ in hepatic venous plasma; $P_{0.4}=$ zero time activity of $\mathrm{CAI}^{131}$ in arterial plasma; $H_{0.4}=$ zero time activity of $\mathrm{CAI}^{131}$ in hepatic venous plasma.

measured and it varied from 65 to 90 per cent (mean 75.8 \pm 11.51 ) and total hepatic blood flow averaged $1,566 \pm 684 \mathrm{ml}$ per minute (Table I).

Group III. Minimal hepatic blood flow averaged $681 \pm 169 \mathrm{ml}$ per minute in 11 patients with cirrhosis and end-to-side portacaval anastamosis and $K$ averaged $0.147 \pm 0.0364 \mathrm{~min}^{-1}$. The means of these parameters were significantly lower than in the control group $(\mathrm{p}<0.001)$ and in the cirrhotic patients in Group II $(0.001<p<0.01)$. The patient with a thrombosed portal vein and cirrhosis had a minimal hepatic blood flow of $380 \mathrm{ml}$ per minute $\left(K=0.102 \mathrm{~min}^{-1}\right)$.

Hepatic extraction of $\mathrm{CAI}^{131}$ was determined in 4 patients with a portacaval anastomosis and in the patient with a thrombosed portal vein, and the average was $89.6 \pm 3.5$ per cent. Total hepatic blood flow averaged $726 \pm 226 \mathrm{ml}$ per minute (Table I).

In Patients 7 and 8 the hepatic extraction of $\mathrm{CAI}^{131}$ and total hepatic blood flow were measured before and after an end-to-side portacaval anastomosis. In Patient 7 (Figure 4) the hepatic extraction of $\mathrm{CAI}^{131}$ rose from 65 to 86 per cent after operation, while the total hepatic blood flow was reduced from 1,480 to $1,070 \mathrm{ml}$ per minute. Minimal hepatic blood flow was reduced from 960 to 920 per minute. In Patient 8 the hepatic extraction of $\mathrm{CAI}^{131}$ of 90 per cent remained unaltered postoperatively while total hepatic blood flow was reduced from 1,190 to $860 \mathrm{ml}$ per minute. Minimal hepatic blood flow was reduced from 1,080 to $780 \mathrm{ml}$ per minute.

Group IV. In 3 patients with normal liver structure and an extrahepatic portal vein obstruction, the minimal hepatic blood flow averaged 837 $\mathrm{ml}$ per minute (range, 510 to 1,230) and $K$ averaged $0.193 \mathrm{~min}^{-1}$. In Patient 16 the hepatic extraction of $\mathrm{CAI}^{131}$ was 92 per cent and the total hepatic blood flow was $550 \mathrm{ml}$ per minute (Table I).

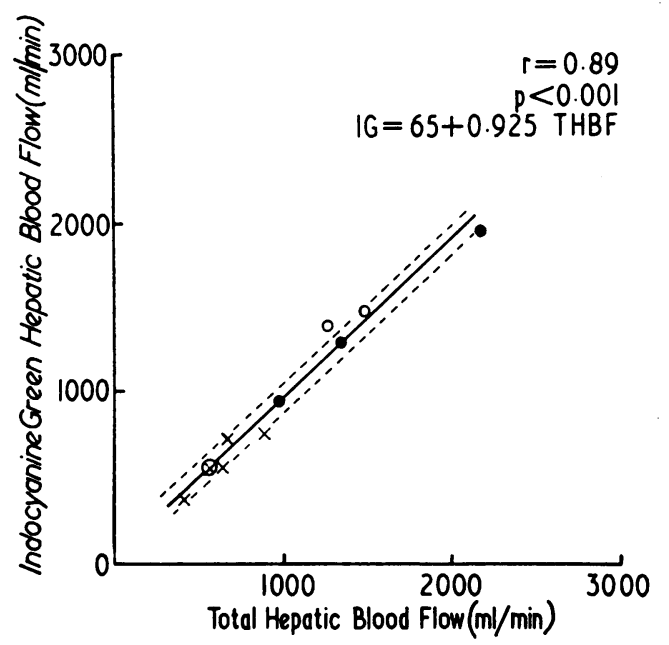

Fig. 5. Correlation of total hepatic blood flow $\left(\mathrm{CAI}^{131}\right.$ ) AND ESTIMATED HEPATIC BLOOD FLOW (INDOCYANINE GREEN IG). = Control subjects (Group I) ; $O=$ patients with cirrhosis and a patent portal vein (Group II) ; $\times=$ patients with cirrhosis and portacaval anastomosis or a thrombosed portal vein (Group III); $\otimes=$ patient with a thrombosed portal vein and a normal liver structure. The dotted lines indicate the 95 per cent confidence limits about the regression line. 


\section{Indocyanine green}

Hepatic blood flow measured with indocyanine green (IG) was estimated in 10 patients (3 control subjects in Group I, 2 cirrhotics in Group II, 3 cirrhotics with a portacaval anastomosis and 1 with a thrombosed portal vein in Group III, and 1 patient with a normal liver and an extrahepatic block in Group IV). The individual results are shown in Table I. There was a highly significant correlation $(R=0.89)$ between the IG flow results and total hepatic blood flow $\left(\mathrm{CAI}^{131}\right)$ results for these patients (Figure 5).

\section{DISCUSSION}

The $\mathrm{CAI}^{131}$ method of measuring liver blood flow without hepatic vein catheterization assumes that the colloid is extracted completely in one passage through the liver. This assumption proved not to be valid, and the flow derived from the disappearance rate constant of $\mathrm{CAI}^{131}$ from peripheral blood, uncorrected for hepatic extraction, underestimated liver blood flow. It has been called "minimal hepatic blood flow." The results obtained for the control group $(1,516 \pm 362 \mathrm{ml}$ per minute; $\left.K=0.339 \pm 0.044 \mathrm{~min}^{-1}\right)$ are similar but higher than those reported by Halpern and co-workers (9) $(1,445 \pm 314 \mathrm{ml}$ per minute ; $K=$ $\left.0.318 \pm 0.050 \mathrm{~min}^{-1}\right)$. However, Halpern did not correct for the slow component of the CAI ${ }^{131}$ peripheral disappearance slope. The probability that the slow component of the plasma colloid disappearance slope represents particles not removed by the liver is suggested by the identical values for the hepatic venous plasma and the peripheral plasma slopes 10 minutes after injection of CAI ${ }^{131}$. Furthermore, with colloidal radioactive chromic phosphate, the slow component slope is absent in peripheral plasma if the colloid is ultracentrifuged before injection and the smaller particles removed (1). In animals, injection of the smaller particles alone results in a prolonged plasma disappearance slope, and, on sacrifice of the animal, the particles are found principally deposited in the bone marrow (1). The biological estimation of the percentage of small particle size of all preparations of $\mathrm{CAI}^{131}$ is an essential prerequisite when this substance is used for estimating liver blood flow. The exclusion of preparations with a high percentage of particles of small size avoids the use of a nonhomogeneous colloid. The mean PSS of 5.77 per cent for this series in humans agrees well with Halpern's figure of 6.4 per cent in guinea pigs.

The hepatic extraction of $\mathrm{CAI}^{131}$ was very high in normal subjects, and Halpern and co-workers (9) also reported a 94 per cent extraction in four normal persons. These results suggest that minimal hepatic blood flow will underestimate true liver blood flow by only less than 10 per cent in patients without liver disease, and this may eliminate the need for hepatic vein catheterization in such subjects.

In patients with hepatic cirrhosis the peripheral method is not usually valid, for hepatic vein catheterization showed that such subjects had a much lower extraction of $\mathrm{CAI}^{131}$ than had subjects without liver disease. $\mathrm{CAI}^{131}$ is removed by the Kupffer cells and the lower extraction could be due to the fact that blood bypasses the sinusoids containing Kupffer cells, to the impairment of Kupffer cell function, or to a reduction in the number of Kupffer cells lining each sinusoid. Morphological evidence favors the first explanation. McIndoe (17) by injection studies showed a very great diminution of the portal sinusoidal bed in cirrhosis. Popper, Elias and Petty (18) have commented on the development of collateral channels between the small portal veins and the small hepatic veins around the regeneration nodules in cirrhosis and have termed these "internal Eck fistulae." However, it is difficult to discount the possibility of disturbed Kupffer cell function, since there is no certain way of evaluating this.

When the portal blood is diverted from the liver either by a surgical portacaval anastomosis or by the development of a collateral circulation after blockage of a main portal vein, a different state of affairs exists. The sinusoids are no longer perfused by portal blood and the portal vein-hepatic vein anastomoses around the nodules are presumably not functioning. The liver is supplied by the hepatic artery which enters the lobule at various levels along the sinusoids (19). On theoretical grounds, therefore, one might expect improvement in the hepatic extraction of $\mathrm{CAI}^{131}$ in the cirrhotic patient when the portal blood stream is diverted from the liver, if the initially low extraction of $\mathrm{CAI}^{131}$ was due to intrahepatic shunting in "internal Eck fistulae" rather than 
to impaired Kupffer cell function. This proved to be the case, for patients with cirrhosis and a portacaval anastomosis had hepatic extraction of 89.6 per cent, which was significantly higher than that in the cirrhotic group with portal venous blood flowing to the liver. Further confirmation of the hypothesis came with the finding of improvement in the hepatic extraction of $\mathrm{CAI}^{131}$ in two patients after end-to-side portacaval anastomosis. In Patient 7 the hepatic extraction of $\mathrm{CAI}^{131}$ rose from 65 to 86 per cent, although hepatic blood flow was reduced by 30 per cent. This improved extraction occurred in the face of worsening hepatocellular function shown by deepening jaundice and a fall in the serum albumin value. Also in keeping with this thesis is the observation that the two cirrhotic patients ( 8 and 11), with almost normal hepatic extraction of $\mathrm{CAI}^{131}$, were shown by the method of Iber, Kerr, Dölle and Sherlock (20) to have an extrahepatic portal collateral flow of over 80 per cent of the total portal venous flow. This evidence suggests that the reduced extraction of $\mathrm{CAI}^{131}$ in cirrhosis is not due to impaired Kupffer cell function. If this were so, one would have to postulate an improvement in Kupffer cell function after portacaval anastomosis, and in one subject in the face of deterioration of hepatocellular function. The alternative explanation that the increased extraction of $\mathrm{CAI}^{131}$ in the shunt patients resulted from a reduction in blood flowing along the sinusoids seems less probable, as the highest extractions were seen in control subjects with rates of liver blood flow significantly higher than in cirrhotic subjects. It seems likely, therefore, that minimal hepatic blood flow determined by this method measures blood flowing through functioning sinusoids. In normal subjects and cirrhotic subjects with portacaval anastomosis and patients in whom portal venous blood is totally diverted from the liver, this value correlates closely with total hepatic blood flow. In patients with cirrhosis and a patent portal vein, minimal hepatic blood is less than total hepatic blood flow (Figure 6).

A reduction in total hepatic blood flow after portacaval anastomosis was seen in Patients 7 and 8 , but in Patient 7 the minimal hepatic blood flow was unaltered postoperatively. This suggests that in certain patients the reduction in hepatic blood flow after portacaval anastomosis $(21,22)$ may not affect liver function if the fraction lost

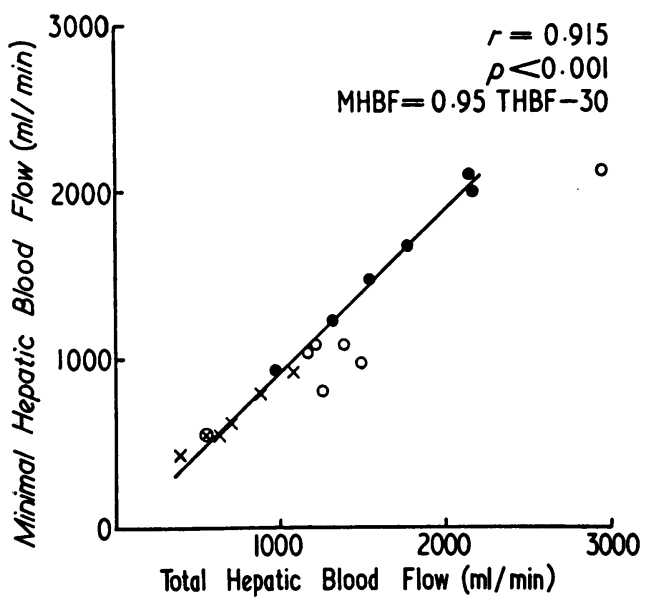

Fig. 6. Correlation of minimal and total hepatic BLOOD FLOW $\left(\mathrm{CAI}^{131}\right)$. $=$ Control subjects (Group I) ; $O=$ patients with cirrhosis and a patent portal vein (Group II) ; $X=$ patients with cirrhosis and a portacaval anastomosis or a thrombosed portal vein (Group III) ; $\otimes=$ patient with a thrombosed portal vein and a normal liver structure (Group IV). The regression line has been calculated for Groups I, III, and IV only. Patients with cirrhosis and a patent portal vein (Group II) are not included on the regression line.

was, in fact, bypassing the hepatic sinusoids before operation.

The measurement of total hepatic blood flow by $\mathrm{CAI}^{131}$ correlated well with hepatic blood flow results determined by indocyanine green, and this suggests that the method does indeed measure liver blood flow. The extrahepatic removal of $\mathrm{CAI}^{131}$ has not been checked in man, but in animals it averages less than 10 per cent (7) and over half of this is allowed for by subtraction of particles of small size. Extrahepatic removal of indocyanine green in man is minimal (11). The slightly higher flow by the CAI ${ }^{131}$ method suggests that its extrahepatic removal may be greater than that of indocyanine green. In patients without a collateral circulation, this factor is not important, since the splenic blood flow is in series with the liver, but in cirrhotics, with an extrahepatic portal collateral circulation, the splenic removal of $\mathrm{CAI}^{131}$ may result in an overestimation of liver blood flow.

With hepatic vein catheterization, the $\mathrm{CAI}^{131}$ method permits an estimation of sinusoidal and intrahepatic shunted blood flow while the constant infusion dye methods (sulfobromophthalein, indocyanine green) measure the sum of these two components. Minimal hepatic blood flow in pa- 
tients with cirrhosis may provide a better understanding of the factors responsible for decompensation in such patients, if one assumes that blood available to the Kupffer cells represents blood available to the hepatic parenchymal cells.

\section{SUMMARY}

The colloidal albumin $\mathrm{I}^{131}$ (CAI ${ }^{131}$ ) method for measuring liver blood flow has been investigated in normal subjects and patients with liver disease. In normal subjects the method is valid without hepatic vein catheterization, since the hepatic extraction of the colloid averaged 94 per cent in one passage through the liver.

In patients with cirrhosis the hepatic extraction of the colloid averaged 75.8 per cent when the portal vein was patent, but rose to 89.6 per cent when the portal vein was disconnected from the liver by a portacaval anastomosis. It is suggested that the reduced hepatic extraction of $\mathrm{CAI}^{131}$ in patients with cirrhosis is due to intrahepatic shunting of colloid which bypasses Kupffer cells in "internal Eck fistulae." Hepatic vein catheterization permits an estimate of this shunting.

Total hepatic blood flow may be calculated from the peripheral colloid blood flow (minimal hepatic blood flow) corrected for hepatic extraction. Total hepatic blood flow measured by colloidal albumin correlated well with hepatic blood flow measured with indocyanine green. Minimal hepatic flow results (uncorrected for hepatic extraction) may be used as an index of hepatic sinusoidal blood flow and as a measure of the functional blood supply to the cirrhotic liver.

\section{APPENDIX}

Preparation of heat-denatured human serum albumin labeled with radioactive iodine $I^{131}$

The procedure was carried out under sterile conditions. All reagents were sterilized prior to use.

1. Denaturation of albumin. The albumin was 97 per cent pure with no added stabilizing agents.

a) The albumin was diluted with normal saline to make a 1 per cent solution containing $8 \mathrm{~g}$ of albumin.

b) The solution was brought to $\mathrm{pH} 7.2$ with $\mathrm{N} \mathrm{NaOH}$.

c) The optical density of the solution was checked in a Unicam spectrophotometer at $500 \lambda$. Optical densities of 0.056 to 0.112 were considered satisfactory.

d) The whole solution was then heated in a flask in a water bath while the flask was shaken continuously. The temperature of the water bath was controlled to bring the solution to $70^{\circ} \mathrm{C}$, and this temperature was maintained for 15 minutes.

$e$ ) The optical density of the solution was read and, if it had risen by $0.168 \mathrm{U}$ above the original reading, heat denaturation was stopped. If not, the flask was heated to $71^{\circ} \mathrm{C}$ for a further 2 minutes and the optical density rechecked. The maximal permissible temperature for denaturation was $75^{\circ} \mathrm{C}$.

f) After satisfactory denaturation, the solution was cooled to $45^{\circ} \mathrm{C}$ under running water and allowed to cool at room temperature until the solution was at $30^{\circ} \mathrm{C}$.

g) $\mathrm{N} \mathrm{HCl}$ was added to obtain a precipitate at $\mathrm{pH} 4.7$ to 5.5. The solution was left to stand for 1 hour.

$h$ ) It was then centrifuged for 15 minutes at 3,500 $\mathrm{rpm}$ and the supernatant fluid was removed and discarded.

i) The solution was washed twice with acidified normal saline solution $(\mathrm{HCl}, \mathrm{pH} 5.5)$ and centrifuged at $3,500 \mathrm{rpm}$ for 15 minutes between washings. The supernatant fluid was checked after the second washing for protein content by the addition of trichloroacetic acid. If a protein precipitate resulted, washings were repeated until the supernatant fluid was free of protein.

j) The precipitate was redissolved in normal saline and brought to $\mathrm{pH} 7.6$ with $\mathrm{N} \mathrm{NaOH}$ and made up to a final volume of 200 to $250 \mathrm{ml}$.

k) The solution was stored at $4^{\circ} \mathrm{C}$ for 24 hours and centrifuged at $3,500 \mathrm{rpm}$ for 15 minutes; the precipitate was discarded.

l) Two $\mathrm{ml}$ of supernatant fluid was removed for protein determination and the remainder tyndallized for 1 hour daily for 3 days at $60^{\circ} \mathrm{C}$. The protein was stored at $4^{\circ} \mathrm{C}$ and was suitable for iodination for up to 3 months.

$m$ ) Protein content of the denatured solution was estimated by weighing the protein precipitated from solution by the addition of trichloroacetic acid. The precipitate was washed with water and acetone and dried to a constant weight.

n) Particle size: Attempts to measure the particle size of the preparation were unsuccessful, since both electronmicroscopy and ultracentrifugation altered the particle size by further denaturation of the colloid. The single component exponential phase of the fast disappearance slope suggested a uniform particle size. The rate of disappearance in control subjects was similar to that of colloidal chromic phosphate $\left(\mathrm{P}^{32}\right)$ with a mean particle size of $200 \AA$ (1).

\section{Iodination of colloidal albumin}

a) One hundred $\mathrm{mg}$ of colloidal albumin (determined from protein estimation) was mixed with $0.8 \mathrm{ml}$ carbonate buffer ( $\mathrm{pH} \mathrm{10)}$ keeping the solution in ice.

b) Twenty to $30 \mathrm{mc}$ of carrier-free $\mathrm{NaI}^{131}$ was made up to a volume of $3 \mathrm{ml}$, and $0.15 \mathrm{ml}$ of $\mathrm{KI}_{3}$ solution $(1,845$ $\mathrm{g}$ per $100 \mathrm{ml}$ of $\mathrm{I}_{2}$ and $2.3 \mathrm{~g}$ of $\mathrm{KI}$ ) was added; a light brown color appeared.

c) The iodine solution was then added drop by drop to the colloidal albumin while the solution was kept in ice.

d) The solution was left at $4^{\circ} \mathrm{C}$ for 2 hours and the activity per unit volume estimated in a well scintillation counter, from a diluted aliquot. 
e) The solution was dialyzed in a sterile cellophane tube suspended in normal saline until no activity was present in the dialyzing fluid. Dialysis was repeated at 36-hour intervals over 3 days.

f) A 2.5 per cent solution of phenol was added to the iodinated albumin to give a concentration of $2.5: 1,000$ of phenol. An aliquot of the solution was plated on agar gel to check its sterility.

g) The activity of the final solution was estimated in a well counter and the fixed total iodine content was calculated. If the iodine content exceeded 1 per cent of the protein, the preparation was discarded.

h) The final total iodine content fixed to the protein was calculated from the amount of iodine added and the efficiency of labeling of the protein with $\mathrm{I}^{131}$. The efficiency of uptake of $\mathrm{I}^{131}=$ activity after dialysis/ activity before dialysis $\times 100$ and ideally ranged from 5 to 15 per cent.

\section{ACKNOWLEDGMENT}

We would like to thank Dr. G. Biozzi for initial supplies of the serum albumin for denaturation, and for subsequent supplies to Dr. W. d'A. Maycock of the Lister Institute, Elstree, Herts. The British Empire Cancer Campaign and Countess Peel Trust helped with expenses.

\section{REFERENCES}

1. Dobson, E. L., and Jones, H. B. The behavior of intravenously injected particulate material. Its rate of disappearance from the blood stream as a measure of liver blood flow. Acta med. scand. 1952, 144, suppl. 273.

2. Vetter, H., Falkner, R., and Neumayr, A. The disappearance rate of colloidal radiogold from the circulation and its application to the estimation of liver blood flow in normal and cirrhotic subjects. J. clin. Invest. 1954, 33, 1594.

3. Vetter, H., Grabner, G., Höfer, R., Neumayr, A., and Parzer, O. Comparison of liver blood flow values estimated by the Bromsulphalein and by the radiogold method. J. clin. Invest. 1956, 35, 825.

4. Vetter, H. Discussion on radiocolloid methods of measuring liver blood flow in Radioaktive Isotope in Klinik und Forschung, $\mathrm{K}$. Fellinger and $\mathrm{H}$. Vetter, Eds. München, Urban \& Schwarzenberg, 1958, p. 135.

5. Playoust, M. R., McRae, J., and Boden, R. W. Inefficient hepatic extraction of colloidal gold: Resulting inaccuracies in determination of hepatic blood flow. J. Lab. clin. Med. 1959, 54, 728.

6. Halpern, B. N., Biozzi, G., Benacerraf, B., Stiffel, C., and Hillenmand, B. Cinétique de la phagocytose d'une sérumalbumine humaine spécialement traitée et radiomarquée, et son application à l'étude de la circulation hépatique chez l'homme. C. R. Soc. Biol. (Paris) 1956, 150, 1307.

7. Benacerraf, B., Biozzi, G., Halpern, B. N., Stiffel, C., and Mouton, D. Phagocytosis of heat-denatured human serum albumin labelled with ${ }^{181} \mathrm{I}$ and its use as a means of investigating liver blood flow. Brit. J. exp. Path. 1957, 38, 35.

8. Biozzi, G., Benacerraf, B., Halpern, B. N., Stiffel, C., and Hillemand, B. Exploration of the phagocytic function of the reticuloendothelial system with heat denatured human serum albumin labeled with $\mathrm{I}^{131}$ and application to the measurement of liver blood flow, in normal man and in some pathologic conditions. J. Lab. clin. Med. 1958, 51, 230.

9. Halpern, B. N., Biozzi, G., Pequignot, G., Delaloye, C., Stiffel, C., and Mouton, D. Mesure de la circulation sanguine du foie et de l'activité phagocytaire du système reticulo-endothelial chez le sujet normal et le sujet cirrhotique. Path. et Biol. 1959, 7, 1637.

10. Bradley, S. E., Ingelfinger, F. J., Bradley, G. P., and Curry, J. J. The estimation of hepatic blood flow in man. J. clin. Invest. 1945, 24, 890.

11. Caesar, J., Shaldon, S., Chiandussi, L., Guevara, L., and Sherlock, S. The use of indocyanine green in the measurement of hepatic blood flow and as a test of hepatic function. Clin. Sci. 1961, 21, 43.

12. Wheeler, H. O., Cranston, W. I., and Meltzer, J. I. Hepatic uptake and biliary excretion of indocyanine green in the dog. Proc. Soc. exp. Biol. (N. Y) 1958, 99, 11.

13. Winkler, K., and Tygstrup, N. Determination of hepatic blood flow in man by Cardio green ${ }^{\circledR}$. Scand. J. clin. Lab. Invest. 1960, 12, 353.

14. Dow, P., and Pickering, R. W. Behavior of dog serum dyed with brilliant vital red or Evans blue toward precipitation with ethanol. Amer. J. Physiol. 1950, 161, 212.

15. Chaplin, H., Jr., and Mollison, P. L. Correction for plasma trapped in the red cell column of the hematocrit. Blood 1952, 7, 1227.

16. Snedecor, G. W. Statistical Methods Applied to Experiments in Agriculture and Biology, 5th ed. Ames, Iowa State College Press, 1956.

17. McIndoe, A. H. Vascular lesions of portal cirrhosis. Arch. Path. (Chicago) 1928, 5, 23.

18. Popper, H., Elias, H., and Petty, D. E. Vascular pattern of the cirrhotic liver. Amer. J. clin. Path. 1952, 22, 717.

19. Elias, $\mathrm{H}$. Re-examination of structure of mammalian liver; the hepatic lobule and its relation to the vascular and biliary systems. Amer. J. Anat. 1949, 85, 379.

20. Iber, F. L., Kerr, D. N. S., Dölle, W., and Sherlock, S. Measurement of blood flow in the collateral vessels of the portal vein; preliminary results of a new method. J. clin. Invest. 1960, 39, 1201.

21. Bradley, S. E., Smythe, C. M., Fitzpatrick, H. F., and Blakemore, A. H. The effect of a portacaval shunt on estimated hepatic blood flow and oxygen uptake in cirrhosis. J. clin. Invest. 1953, 32, 526.

22. Redeker, A. G., Geller, H. M., and Reynolds, T. B. Hepatic wedge pressure, blood flow, vascular resistance and oxygen consumption in cirrhosis before and after end-to-side portacaval shunt. J. clin. Invest. 1958, 37, 606. 